(2) Open Access Full Text Article

\title{
Knowledge and Attitude of the Medical Staff Concerning Cardiac Rehabilitation in Zhejiang Province, China: A Cross-Sectional Study
}

This article was published in the following Dove Press journal: Patient Preference and Adherence

\author{
Haixiang Zhu (iD ${ }^{\prime}$ \\ Zhihong $\mathrm{Ye} \mathbb{D}^{2}$ \\ Li Ning (ID $)^{3}$ \\ Xiaoxue Han $\mathbb{1}^{\prime}$ \\ Yuan Wu (D) \\ 'Department of Cardiology, Zhejiang \\ University School of Medicine Sir Run \\ Run Shaw Hospital, Hangzhou, People's \\ Republic of China; ' 2 Department of Lead's \\ Office, Zhejiang University School of \\ Medicine Sir Run Run Shaw Hospital, \\ Hangzhou, People's Republic of China; \\ ${ }^{3}$ Nursing Department, Hangzhou First \\ People's Hospital, Hangzhou, People's \\ Republic of China
}

Purpose: This study aimed to investigate the status of cardiac rehabilitation knowledge and attitude of the medical staff.

Patients and Methods: A questionnaire survey of doctors and nurses was performed in the departments of cardiology of 7 teaching hospitals with attitudes, knowledge toward CR in Zhejiang Province, China, from April to September 2018, to assess Chinese medical staff for the degree of mastery and attitude toward cardiac rehabilitation.

Results: A total of 160 questionnaires were distributed and 152 valid were collected. The responding individuals included 106 nurses (69.74\%) and 46 doctors $(30.26 \%)$. The scores of cardiac rehabilitation knowledge were $56.68 \pm 5.06$, and those of cardiac rehabilitation attitude were $15.19 \pm 3.86$. Subgroup analysis showed the lower the job title $(\mathrm{P}<0.001)$, the lower the educational level $(\mathrm{P}=0.011)$, and the shorter the years of specialty experience $(\mathrm{P}=0.005)$, the more negative the attitude toward cardiac rehabilitation.

Conclusion: The medical staff has a good mastery of cardiac rehabilitation knowledge. But we also find that staffs with lower education level and job title, shorter specialty work experience were associated with a more negative attitude toward implement rehabilitation.

Keywords: cardiac rehabilitation, acute myocardial infarction, knowledge, attitude, medical staff

\section{Introduction}

Cardiovascular diseases (CVDs) represent the top cause of mortality around the world, with about 17.5 million patients succumbing to different heart diseases, including coronary heart disease (CHD), stroke, rheumatic heart, and myocardial infarction (MI). ${ }^{1}$ Currently, acute myocardial infarction (AMI) is the leading cause of death among Chinese individuals, ${ }^{2}$ accounting for more than $40 \%$ of all deaths. ${ }^{3}$ In recent years, CVD incidence and the total disease burden have steadily increased. ${ }^{4}$ Cardiac rehabilitation (CR) was a cost-effective way to provide secondary prevention services that can reduce cardiovascular morbidity and mortality in patients with cardiovascular disease (CVD). ${ }^{5-7}$

There is an overwhelming evidence of the efficacy of secondary prevention initiatives including cardiac rehabilitation in terms of reduction in morbidity and mortality. ${ }^{8}$ Although the benefits of cardiac rehabilitation have been clearly demonstrated, the proportion of AMI patients receiving this treatment is relatively low, with only $30-40 \%$ in European and American countries. ${ }^{9-11}$ Studies in China ${ }^{12,13}$ showed that less than $10 \%$ of Chinese CVD patients are administered cardiac rehabilitation. Previous
Correspondence: Haixiang Zhu Department of Cardiology, Zhejiang University School of Medicine Sir Run Run Shaw Hospital, Hangzhou, People's Republic of China

Tel +86- I 3757| 29895

Fax +86-57187887872

Email 3203070@zju.edu.cn
Patient Preference and Adherence 2020:14 |77|-1777

|77|

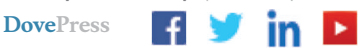

http://doi.org/10.2147/PPA.\$270503 
reports ${ }^{14,15}$ found that the factors affecting the implementation of cardiac rehabilitation include age, gender, health condition, knowledge of cardiac rehabilitation services by the patient, CVD perception, financial power, and occupational constraints. ${ }^{15}$ Our research team previously investigated patients with AMI in Zhejiang Province for knowledge of and attitude toward cardiac rehabilitation, ${ }^{16}$ and found that the factors affecting the patients' participation in rehabilitation include age, the knowledge level of cardiac rehabilitation, and economic burden. Specifically, resistance to rehabilitation was shown to increase with age; meanwhile, the lower the rehabilitation knowledge and/or the more serious the economic burden, the higher the resistance.

However, whether knowledge mastery and attitude toward cardiac rehabilitation of Chinese medical staff play a role in the utilization of this treatment remains unclear. In order to more comprehensively analyze the factors affecting cardiac rehabilitation, we conducted a survey of the medical staff in the Cardiology Departments of 7 hospitals in Zhejiang Province, China.

\section{Materials and Methods Study Design}

A questionnaire survey of doctors and nurses was performed in the Departments of cardiology of 7 teaching hospitals with AMI treatment capacity in Zhejiang Province, China, from April to September 2018, to assess Chinese medical staff for the degree of mastery of and attitude toward cardiac rehabilitation. The medical staff in these institutions were invited to fill out a questionnaire. Informed consent was obtained from all participants before survey initiation. Inclusion criteria were: (1) doctor or nurse in one of the participating hospitals with professional qualification certification; (2) More than 2 years of work in cardiovascular department . Exclusion criteria were: (1) unwillingness to participate in the study; (2) visiting or rotating physician from other departments.

The study protocol was approved by the ethics committee of Sir Run Run Shaw Hospital, Zhejiang University School of Medicine (ethics number: 20180516-060).

\section{Patient and Public Involvement Statement}

In this study, respondents were informed of the purpose of the investigation, matters needing attention, conflicts of interest and confidentiality of information in the form of informed consent. The survey was conducted anonymously, and the survey results were presented to the subjects in the form of literature publication. The study was conducted on a fully informed and consensual basis, and no investigators were recruited as it did not involve clinical trials.

\section{Questionnaire Development}

The "Questionnaire of factors affecting nursing staff's willingness to undertake cardiac rehabilitation" compiled by Tao et $\mathrm{al}^{17}$ (retest reliability and Cronbach's $\alpha$ reliability coefficient of 0.903 and 0.872 , respectively) was taken as a basis for the current survey, with few questions revised according to the study needs. The final questionnaire was generated by cardiology experts after three rounds of discussion, and included 3 parts. The first portion encompassed the general information, with 6 domains: work position, gender, education level, technical title, years of experience, and working years in cardiovascular medicine. The second part included questions about the knowledge of cardiac rehabilitation, with 12 domains and a total of 74 knowledge questions: concept, content, indications and contraindications, and monitoring indicators of cardiac rehabilitation, etc. A correct answer was recorded as 1 point, and a wrong one as 0 point, for a total maximum score of 74 points. The higher the total score, the better the participant's mastery of cardiac rehabilitation knowledge. The third part had questions related to staff attitude toward cardiac rehabilitation, and encompassed cognitive attitude (4 domains), promoting factors of cardiac rehabilitation (6 domains) and obstructive factors of cardiac rehabilitation (8 domains), with a total of 18 items. The 5-level Likert scoring method was used for each item. Forward scoring questions were scored 1 to 5 points from "completely disagree" to "fully agree", respectively, while reverse scoring questions were scored 1 to 5 points from "fully agree" to "completely disagree", respectively. After questionnaire compiling was completed, 10 cardiology staff meeting the above eligibility criteria in a tertiary hospital were selected for a preliminary study; the original survey participants were retested with the same questionnaire a week later, and a retest reliability of 0.896 was obtained. Based on the results, the questionnaire content that may be ambiguous was slightly modified, and a final draft was obtained.

\section{Data Collection and Quality Control}

Before the survey, the principal investigator provided homogeneous training to all surveyors, addressing the survey process and tools, significance of questionnaire entries, and precautions during the survey. Each hospital appointed a trained surveyor to administer the questionnaires. During the survey, a unified instruction from was used to explain the research purpose and questionnaire requirements to all respondents in detail. After respondent consent, the questionnaire 
was filled out anonymously. For problems encountered by the respondent, investigators used the unified instruction form to further explain. The filling time was 20 to 30 mins. The filled questionnaires were recovered on-site. Questionnaire data were entered uniformly. A questionnaire was considered to be invalid with more than $15 \%$ of the included options not selected. ${ }^{18}$ After original data were entered, they were doublechecked by another member to ensure the correctness of data entry.

\section{Calculate Methods}

The scores of knowledge questionnaire were judged by percentage. The scores of 60-79 were moderate, 80-100 were good and less than 60 were poor. $\mathrm{P}<0.05$ was considered statistically significant among groups in attitude evaluation of medical staff with different characteristics, that is, there were differences in attitude to rehabilitation among groups.

\section{Statistical Methods}

SPSS 23.0 (IBM, NY, USA) was used for data analysis. Measurement data with normal distribution are mean \pm standard deviation (SD), and were assessed by one-way analysis of variance (ANOVA), with post hoc pairwise comparisons for determining between-group differences. Measurement data with skewed distribution were presented as median and quartile; the Kruskal-Wallis $H$-test was performed for comparing multiple groups, and the Mann-Whitney $U$-test for group-pair comparisons. Count data were described by number of cases (percentage), and assessed by the Chi-square test or Fisher exact test. $\mathrm{P}<0.05$ was considered statistically significant.

\section{Results}

\section{General Data}

A total of 160 questionnaires were distributed in this study, of which 8 were removed due to incomplete answers. Therefore, 152 valid questionnaires were retrieved, indicating a response rate of $95 \%$.

Of the 152 responders, $55(36.2 \%)$ and 97 (63.8\%) were male and female, respectively. They comprised 106 nurses $(69.7 \%)$ and 46 doctors $(30.3 \%)$, with an average medical work experience of 5.0 (ranging from 3.0 to 12.8) years; cardiovascular medical work experience averaged 4.0 (ranging from 1.0 to 6.0$)$ years. A total of $23(15.1 \%), 109$ (71.7\%) and $20(13.2 \%)$ participants had junior college education, a bachelor's degree and a master's degree or above, respectively. Regarding job title, 94 (61.9\%), 44 (28.9\%) and 14
$(9.2 \%)$ responders had primary, intermediate and senior titles, respectively (Table 1 ).

\section{Mastery of Cardiac Rehabilitation Knowledge}

The questions assessing the knowledge of the medical staff on cardiac rehabilitation are provided in Supplement S1. The total score for cardiac rehabilitation knowledge was 74 points, and the medical staff scored averagely 58, which translates to 80 points on a 100-point scale. Subgroup analysis based on gender, occupation, education level, job title, work experience, and specialty work experience showed no significant differences in knowledge scores $(\mathrm{p}>0.01)$ (Table 2).

\section{Attitudes of the Medical Staff Toward Cardiac Rehabilitation}

The questions related to the attitudes of the medical staff on cardiac rehabilitation are summarized in Supplement S2. The scores for cognitive attitudes of the medical staff toward the

Table I General Participants

\begin{tabular}{|c|c|c|}
\hline Characteristic & $\mathbf{N}(\%)$ & $\begin{array}{l}\text { Median } \\
(\mathbf{Q} \text { I, Q3) }\end{array}$ \\
\hline \multicolumn{3}{|l|}{ Gender } \\
\hline Male & $55(36.2 \%)$ & \\
\hline Female & 97 (63.8\%) & \\
\hline \multicolumn{3}{|l|}{ Occupation } \\
\hline Doctor & $46(30.3 \%)$ & \\
\hline Nurse & $106(69.7 \%)$ & \\
\hline \multicolumn{3}{|l|}{ Education level } \\
\hline Junior college & $23(15.1 \%)$ & \\
\hline Bachelor's degree & 109 (71.7\%) & \\
\hline Master's degree and above & $20(13.2 \%)$ & \\
\hline \multicolumn{3}{|l|}{ Job title } \\
\hline Primary & $94(61.9 \%)$ & \\
\hline Intermediate & 44 (28.9\%) & \\
\hline Senior & 14 (9.2\%) & \\
\hline Work experience (years) & & $5.0(3.0,12.8)$ \\
\hline$<5$ & $57(37.5 \%)$ & \\
\hline$(5-10)$ & $54(35.5 \%)$ & \\
\hline$\geq 4$ & $4 \mathrm{I}(27.0 \%)$ & \\
\hline $\begin{array}{l}\text { Specialty work experience } \\
\text { (years) }\end{array}$ & & $4.0(1.0,6.0)$ \\
\hline$<5$ & $95(62.5 \%)$ & \\
\hline$(5-10)$ & $29(19.1 \%)$ & \\
\hline$\geq 10$ & $28(18.4 \%)$ & \\
\hline
\end{tabular}


Table 2 Medical Personnel's Knowledge of Cardiac Rehabilitation

\begin{tabular}{|c|c|c|}
\hline Characteristic & $\begin{array}{l}\text { Knowledge } \\
\text { Score }\end{array}$ & $P$ value \\
\hline \multicolumn{3}{|l|}{ Gender } \\
\hline Male & $58.0(55.0,61.0)$ & 0.581 \\
\hline Female & $58.0(54.0,60.0)$ & \\
\hline \multicolumn{3}{|l|}{ Occupation } \\
\hline Doctor & $59.5(55.5,60.5)$ & 0.098 \\
\hline Nurse & $58.0(54.0,60.0)$ & \\
\hline \multicolumn{3}{|l|}{ Education level } \\
\hline Junior college & $57.0(54.0,59.0)$ & 0.363 \\
\hline Bachelor's degree & $58.0(54.0,60.0)$ & \\
\hline Master's degree and above & $58.5(55.0,60.5)$ & \\
\hline \multicolumn{3}{|l|}{ Job title } \\
\hline Primary & $57.0(54.0,59.0)$ & 0.058 \\
\hline Intermediate & $59.0(55.5,60.0)$ & \\
\hline Senior & $60.0(56.0,60.0)$ & \\
\hline \multicolumn{3}{|l|}{ Work experience (years) } \\
\hline$<5$ & $56.5(53.0,59.0)$ & 0.105 \\
\hline$(5-10)$ & $58.0(55.0,60.0)$ & \\
\hline$\geq 10$ & $59.0(56.0,60.0)$ & \\
\hline \multicolumn{3}{|l|}{$\begin{array}{l}\text { Specialty work experience } \\
\text { (years) }\end{array}$} \\
\hline$<5$ & $58.0(54.0,60.0)$ & 0.247 \\
\hline$(5-10)$ & $56.0(53.0,60.0)$ & \\
\hline$\geq 10$ & $58.5(56.0,60.0)$ & \\
\hline
\end{tabular}

application of cardiac rehabilitation are shown in Table 3. The total score for this part ranged from 0 to 20. Regarding the overall tendency to perform cardiac rehabilitation, 144 (94.7\%) of the 152 respondents indicated that they agreed (4 points) or "strongly agreed" (5 points). There was no significant difference between males and females $(\mathrm{P}=0.091)$. The scores of doctors were higher than those of nurses (16.0 [16.0 to 18.0 ] versus 14.5 [13.0 to 16.0 ]; $\mathrm{P}=0.004)$. Significant score differences were found among various education groups $(\mathrm{P}<0.001)$, with scores in responders with a master's degree and above (17.0 [16.0 to 18.0]) $>$ bachelor's degree (15.0 [13.0 to 16.0]) > Junior college (14.0 [12.0 to 16.0]). There were significant score differences among groups with different job titles $(\mathrm{P}<0.001)$ : senior title $(16.5$ $[15.0$ to 18.0$])>$ intermediate title $(16.0[14.5$ to 17.0$])>$ primary title (14.0 [12.0 to 16.0]). Staff with different working years showed significant score differences $(\mathrm{P}=0.011)$; the greater the work experience, the higher the score. Likewise, groups with different years of specialty work
Table 3 Scores of Attitudes Toward Cardiac Rehabilitation

\begin{tabular}{|c|c|c|}
\hline Characteristic & Attitude Score & $P$ value \\
\hline \multicolumn{3}{|l|}{ Gender } \\
\hline Male & $16.0(15.0,17.0)$ & 0.091 \\
\hline Female & $15.0(13.0,16.0)$ & \\
\hline \multicolumn{3}{|l|}{ Occupation } \\
\hline Doctor & $16.0(16.0,18.0)$ & 0.004 \\
\hline Nurse & I4.5 (I3.0,16.0) & \\
\hline \multicolumn{3}{|l|}{ Education level } \\
\hline Junior college & $14.0(12.0,16.0)$ & $<0.001$ \\
\hline Bachelor's degree & $15.0(13.0,16.0)$ & \\
\hline Master's degree and above & $17.0(16.0,18.0)$ & \\
\hline \multicolumn{3}{|l|}{ Job title } \\
\hline Primary & $14.0(12.0,16.0)$ & $<0.001$ \\
\hline Intermediate & $16.0(14.5,17.0)$ & \\
\hline Senior & $16.5(15.0,18.0)$ & \\
\hline \multicolumn{3}{|l|}{ Work experience (years) } \\
\hline$<5$ & $14.0(13.0,16.0)$ & 0.011 \\
\hline$(5-10)$ & $14.0(12.0,16.0)$ & \\
\hline$\geq 10$ & $16.0(14.0,17.0)$ & \\
\hline \multicolumn{3}{|l|}{ Specialty work experience (years) } \\
\hline$<5$ & $14.0(13.0,16.0)$ & 0.005 \\
\hline$(5-10)$ & $15.0(12.0,16.0)$ & \\
\hline$\geq 10$ & $16.0(15.0,18.0)$ & \\
\hline
\end{tabular}

showed significant score differences $(\mathrm{P}=0.005)$; the greater the specialty work experience, the higher the score.

The obstructive factors of cardiac rehabilitation according to the medical staff are shown in Table 4. No personal benefit in carrying out cardiac rehabilitation(70.4\%), No peersupport from other medical satff (56\%) were the top two obstructive factors.

The promoting factors of cardiac rehabilitation according to the medical staff are shown in Table 5. Possibility of acquiring additional knowledge and skills (97.37\%), increasing the cardiology team's influence and attracting more attention from the hospital (94.08\%), and strengthening collaboration among doctors, nurses, rehabilitators and other medical staff (94.08\%) were the top factors.

\section{Discussion}

This cross-sectional study performed in 7 teaching hospitals in Zhejiang Province demonstrated that the medical staff has a good mastery of cardiac rehabilitation knowledge; in addition, we found that the lower the education level and job title, and the shorter the years of specialty work experience, the more negative the attitude toward rehabilitation. 
Table 4 Obstructive Factors of Cardiac Rehabilitation According to the Medical Staff

\begin{tabular}{|l|l|}
\hline Items & $\begin{array}{l}\text { Agree } \\
\text { (\%)* }\end{array}$ \\
\hline No personal benefit in carrying out cardiac rehabilitation & $70.4^{*}$ \\
\hline $\begin{array}{l}\text { Most medical staff do not support early exercise for } \\
\text { patients with acute myocardial infarction (no peer- } \\
\text { support) }\end{array}$ & $56^{*}$ \\
\hline $\begin{array}{l}\text { Daily work exhausting the medical staff, with no time to } \\
\text { assist patients in rehabilitation exercises }\end{array}$ & 30.93 \\
\hline $\begin{array}{l}\text { Current lack of clear clinical pathways/guidelines, } \\
\text { allowing effective rehabilitation activities }\end{array}$ & 29.61 \\
\hline $\begin{array}{l}\text { Belief of patients and family members that patients } \\
\text { should lay in bed for rest after acute myocardial } \\
\text { infarction, and patient unwillingness to exercise }\end{array}$ & 29.60 \\
\hline $\begin{array}{l}\text { Current lack of cardiac rehabilitation sites and } \\
\text { equipment allowing effective rehabilitation activities }\end{array}$ & 26.32 \\
\hline $\begin{array}{l}\text { Lack of legal provisions for cardiac rehabilitation } \\
\text { doctors/nurses, and no legal protection while applying } \\
\text { cardiac rehabilitation }\end{array}$ & 37 \\
\hline $\begin{array}{l}\text { Tense conflicts between doctors and patients/worry } \\
\text { about medical disputes caused by condition changes } \\
\text { during rehabilitation }\end{array}$ & 19.08 \\
\hline Notes: Refred to proporton of responders seleting & \\
\hline$g r e \%$ & $(4$ poins) \\
\hline
\end{tabular}

Notes: Referred to the proportion of responders selecting "agree" (4 points) or "completely agree" (5 points) for the item. *The most top items of obstructive factors.

At present, the main factors hindering the clinical application of cardiac rehabilitation include no direct benefits to doctors/nurses, difficulty in gathering peers for the therapy, and the unwillingness of most patients to cooperate. The present findings provided a direct and powerful basis for subsequent targeted promotion of cardiac rehabilitation in China.

This study found that all the surveyed medical staff had a high degree of knowledge in cardiac rehabilitation, which may reflect the increase in cardiac rehabilitation training performed in China in recent years. Indeed, cardiovascular rehabilitation knowledge has been disseminated in various cardiovascular communication conferences, continually confirming the benefits of cardiac rehabilitation. ${ }^{5-7}$ Chinese medical workers paid attention to and learned about cardiac rehabilitation.

As shown above, there were significant differences in the attitudes of the medical staff toward the application of cardiac rehabilitation: the lower the education level, the lower the job title, and the shorter the specialty work experience,
Table 5 Factors Promoting the Application of Cardiac Rehabilitation by the Medical Staff

\begin{tabular}{|l|l|}
\hline Items & $\begin{array}{l}\text { Agree } \\
(\%)^{*}\end{array}$ \\
\hline $\begin{array}{l}\text { Knowledge and skills acquired while performing cardiac } \\
\text { rehabilitation }\end{array}$ & $97.37^{*}$ \\
\hline $\begin{array}{l}\text { Increased cardiology team influence, making hospitals } \\
\text { pay more attention to the cardiology department. }\end{array}$ & 94.08 \\
\hline $\begin{array}{l}\text { Strengthening of collaboration of doctors, nurses, } \\
\text { rehabilitators and other medical staff. }\end{array}$ & 94.08 \\
\hline Increased sense of worth in doctors and nurses & 84.87 \\
\hline $\begin{array}{l}\text { Cardiac rehabilitation allows patients and family } \\
\text { members to give higher ratings to doctors/nurses. }\end{array}$ & 82.89 \\
\hline $\begin{array}{l}\text { Cardiac rehabilitation can prevent the loss of patient } \\
\text { resource }\end{array}$ & 77.63 \\
\hline
\end{tabular}

Notes: Referred to the proportion of responders selecting "agree" (4 points) or "completely agree" ( 5 points) for the item. *The most significant item is the highest percentage.

the more negative the attitude toward rehabilitation. This indicates that despite the overall great knowledge of cardiac rehabilitation demonstrated by doctors and nurses, their attitudes toward the therapy were not always positive, which restricts the application of cardiac rehabilitation. These results were consistent with those of Liu et al. ${ }^{19}$ Specifically, the medical professionals with intermediate and senior titles were more enthusiastic compared with their peers holding primary titles. This may be related to increased opportunities for reeducation for more experienced professionals, with new technologies and concepts exposed in clinical practice. With prolonged specialty work experience, individuals are more likely to embrace new concepts in their field. These results also suggested that the concept of cardiac rehabilitation is not yet widespread among young Chinese doctors and nurses. Studies of European populations ${ }^{20}$ also showed that postgraduate courses on cardiovascular prevention and rehabilitation are few, with the topics covered being quite different. Because the attitude of the medical staff toward cardiac rehabilitation directly affects the therapeutic process, ${ }^{21}$ setting up cardiac rehabilitationrelated courses and providing sufficient training on cardiovascular prevention and rehabilitation could greatly improve the attitude of health professionals with low job titles. Since effective implementation of cardiac rehabilitation after CVD remains (participation rate $<50 \%$ ) despite international recommendations, ${ }^{22}$ cardiac rehabilitation should be considered an industry standard for coronary heart disease 
treatment. The present findings also suggest that in the practice of clinical rehabilitation, managers should pay more attention to the associated concepts and attitudes of young clinicians with low job titles and education levels, providing more opportunities to contribute to academic communications and encouraging them to actively participate in clinical decision-making. This would help young and/or lowly educated health professionals pay more attention to the development of the field and improve their attitudes toward the therapy. The medical staff with middle and high job titles should also be encouraged to lead in sharing their experiences (information and ideas related to the field) with those with low job titles and short specialty work experience, spreading the concept of cardiac rehabilitation.

The current survey identified a few obstructive factors of cardiac rehabilitation, with no direct benefit to the staff, no peer support, and non-cooperation of patients as the main ones. Previous findings have revealed the obstructive influencing factors of cardiac rehabilitation and related interventions. ${ }^{16}$ Therefore, it was suggested that it is necessary to strengthen patients' education and attitude toward rehabilitation, while educating the medical staff in cardiac rehabilitation. "Cardiac rehabilitation does not bring any benefit to the medical staff" ranked first among all obstructive factors. This indicates that the medical staff felt that the cost and benefits of cardiac rehabilitation are far from compensating their efforts, corroborating Moradi et al. ${ }^{11}$ Also, this finding reflected the actual views and attitudes of the medical staff on the benefits of cardiac rehabilitation. Indeed, cardiac rehabilitation requires long-term investment, and short-term benefits are unclear. ${ }^{23,24}$ In China, operations of cardiac rehabilitation are timeconsuming but relatively less expensive. It is necessary to further increase the enthusiasm of the medical staff for cardiac rehabilitation and promote its application.

This study had some limitations. The research participants were all medical staff of cardiology departments of teaching hospitals in Zhejiang Province, not including rehabilitation technicians who account for a certain percentage in cardiac rehabilitation work force, and the majority of questionnaires' responders were nurses. Maybe in most of the reports, there are only doctors could refer to CR services and reports are lacking on the effect of nurse-led cardiac rehabilitation intervention on cardiac risk factors. But we were delighted to find Xiaolian Jiang's ${ }^{25}$ study clearly indicates the benefits of a nurse-led cardiac rehabilitation intervention on health behaviour improvement and cardiac physiological risk reduction of $\mathrm{CHD}$ patients that findings may be suggestive of the development of evidence-based practice in transitional nursing care as well as for future research. Besides that, the response rate in both groups of the participants was low, such as there are only 46 doctors responded for it. A more complete data collection could help us finding more variables difference among medical staff. In the future, the research focus should be further expanded to include all health professionals involved in this treatment. Similar investigations and intervention studies should be carried out in other regions and hospitals with different grades and adequate sample size. Finally, this was a cross-sectional study, with inherent shortcomings.

\section{Conclusions}

The medical staff's knowledge of cardiology rehabilitation in Zhejiang Province is generally good. However, the wiliness to conduct cardiac rehabilitation may be lower in the respondents with low job titles and/or education level. No benefits, no peer-support and the non-cooperation of patients are the main obstructive factors of cardiac rehabilitation in the medical staff.

\section{Ethics Approval and Informed Consent}

The study protocol was approved by the ethics committee of Sir Run Run Shaw Hospital, Zhejiang University School of Medicine (ethics number: 20180516-060).

\section{Acknowledgments}

We sincerely acknowledge the study participants, without whose contributions this research would not have been possible. We are grateful to Jinhua Jin, Xueqin Yu, Xiaohui Xue, Feilin Wang, and the Department of Cardiology in SRRSH, who participated in the survey design and data collection. We also gratefully acknowledge help from the anonymous referees and journal editors in the preparation of this manuscript.

\section{Author Contributions}

Haixiang Zhu carried out the studies, participated in collecting data, and drafted the manuscript. Zhihong Ye and Li Ning performed the statistical analysis and participated in its design. Xiaoxue Han and Yuan Wu participated in acquisition, analysis, or interpretation of data and draft the manuscript. All authors contributed to data analysis, drafting or revising the article, have agreed on the journal to which the article will be submitted, gave final approval of 
the version to be published, and agree to be accountable for all aspects of the work.

\section{Funding}

The study was funded by the Medical and Health Science and Technology Fund Project of Zhejiang Province (No. 2020KY582) and the Nursing Research Fund Project of Sir Run Run Shaw Hospital, Zhejiang University School of Medicine (No. 201916HL).

\section{Disclosure}

The authors report no conflicts of interest in this work.

\section{References}

1. Shi A, Tao Z, Wei P, Zhao J. Epidemiological aspects of heart diseases. Exp Ther Med. 2016;12 (3):1645-1650. doi:10.3892/etm.2016.3541

2. Yang G, Wang Y, Zeng Y, et al. Rapid health transition in China, 1990-2010: findings from the Global Burden of Disease Study 2010. Lancet. 2013;381 (9882):1987-2015. doi:10.1016/S0140-6736(13) 61097-1

3. Zhou M, Wang H, Zhu J, et al. Cause-specific mortality for 240 causes in China during 1990-2013: a systematic subnational analysis for the Global Burden of Disease Study 2013. Lancet. 2016;387 (10015):251-272. doi:10.1016/S0140-6736(15)00551-6

4. Zhao D, Liu J, Wang M, Zhang X, Zhou M. Epidemiology of cardiovascular disease in China: current features and implications. Nat Rev Cardiol. 2019;16 (4):203-212. doi:10.1038/s41569-018-0119-4

5. Goel K, Lennon RJ, Tilbury RT, Squires RW, Thomas RJ. Impact of cardiac rehabilitation on mortality and cardiovascular events after percutaneous coronary intervention in the community. Circulation. 2011;123 (21):2344-2352. doi:10.1161/CIRCULATIONAHA.110. 983536

6. Lavie CJ, Milani RV. Cardiac rehabilitation and exercise training in secondary coronary heart disease prevention. Prog Cardiovasc Dis. 2011;53 (6):397-403. doi:10.1016/j.pcad.2011.02.008

7. Lawler PR, Filion KB, Eisenberg MJ. Efficacy of exercise-based cardiac rehabilitation post-myocardial infarction: a systematic review and meta-analysis of randomized controlled trials. Am Heart J. 2011;162 (4):571-584.e572. doi:10.1016/j.ahj.2011.07.017

8. Piepoli MF, Corra U, Adamopoulos S, et al. Secondary prevention in the clinical management of patients with cardiovascular diseases. Core components, standards and outcome measures for referral and delivery: a policy statement from the cardiac rehabilitation section of the European Association for Cardiovascular Prevention \& Rehabilitation. Endorsed by the Committee for Practice Guidelines of the European Society of Cardiology. Eur J Prev Cardiol. 2014;21 (6):664-681. doi:10.1177/2047487312449597

Patient Preference and Adherence

\section{Publish your work in this journal}

Patient Preference and Adherence is an international, peer-reviewed, open access journal that focusing on the growing importance of patient preference and adherence throughout the therapeutic continuum. Patient satisfaction, acceptability, quality of life, compliance, persistence and their role in developing new therapeutic modalities and compounds to optimize clinical outcomes for existing disease
9. Hutchinson P, Meyer A, Marshall B. Factors influencing outpatient cardiac rehabilitation attendance. Rehabil Nurs. 2015;40 (6):360-367. doi:10.1002/rnj.202

10. Oosenbrug E, Marinho RP, Zhang J, et al. Sex differences in cardiac rehabilitation adherence: a meta-analysis. Can J Cardiol. 2016;32 (11):1316-1324. doi:10.1016/j.cjca.2016.01.036

11. Moradi B, Maleki M, Esmaeilzadeh M, Abkenar HB. Physicianrelated factors affecting cardiac rehabilitation referral. $J$ Tehran Heart Cent. 2011;6 (4):187-192.

12. Liu J, Qian Q, University NM, Cardiology DO. Investigation about the patients' demands for cardiac rehabilitation. J Nantong Univ. 2017.

13. Cao X. Investigation and analysis on the status of stage I cardiac rehabilitation in 25 hospitals in Guangdong Province. J Nurs. 2012;6 (19):28-30.

14. McLachlan A, Doolan-Noble F, Lee M, McLean K, Kerr AJ. The electronic tracking of referral and attendance at cardiac rehabilitation in Counties Manukau Health: a potential model for New Zealand. N Z Med J. 2016;129 (1446):64-71.

15. Sumner J, Grace SL, Doherty P. Predictors of cardiac rehabilitation utilization in England: results from the national audit. $J$ Am Heart Assoc. 2016;5 (10). doi:10.1161/JAHA.116.003903

16. Zhu H, Ye Z, Jin J. Investigation on knowledge and attitude of cardiac rehabilitation in patients with acute myocardial infarction. Chin J Nurs. 2020;1 (5):78-83.

17. Tao XJ, Ying WU, Zhang Y, Nursing SO, University CM. Nurse' willingness of early cardiac rehabilitation in patients with acute myocardial infarction and its influence factors. J Nurs. 2015.

18. Earl B, Qiu Z. Social Research Methodology. 11th ed. Beijing: Huaxia Publishing House; 2009:262.

19. Liu S, Zhan Y, Hui Z. Analysis of the status quo and influencing factors of cardiac rehabilitation KAP of nursing personnel. Chin Nurs Res. 2015.

20. Marques-Vidal P, Saner H. Postgraduate teaching of cardiovascular prevention and rehabilitation in Europe: first results. Eur J Cardiovasc Prev Rehabil. 2010;17 (5):613-614. doi:10.1097/ HJR.0b013e3283384bc8

21. Lucky R, Edward N, Kent T. Physician factors affecting cardiac rehabilitation referral among cardiac specialists: the Philippine Heart Center CRAVE study (Cardiac Rehabilitation Attitudes and Viewpoints on Engagement). $J$ Clin Prev Cardiol. 2016;2 (5):44-50.

22. Dalal HM, Doherty P, Taylor RS. Cardiac rehabilitation. BMJ. 2015;351:h5000.

23. Reich B, Benzer W, Harpf H, et al. Efficacy of extended, comprehensive outpatient cardiac rehabilitation on cardiovascular risk factors: a nationwide registry. Eur J Prev Cardiol. 2020;20474 87319898958.

24. Anderson L, Nguyen TT, Dall CH, Burgess L, Bridges C, Taylor RS. Exercise-based cardiac rehabilitation in heart transplant recipients. Cochrane Database Syst Rev. 2017;4:CD012264.

25. Jiang X, Sit JW, Wong TK. A nurse-led cardiac rehabilitation programme improves health behaviours and cardiac physiological risk parameters: evidence from Chengdu, China. J Clin Nurs. 2007;16 (10):1886-1897. doi:10.1111/j.1365-2702.2007.01838.x 